\title{
House Dust Mite-Specific Sublingual Immunotherapy Prevents the Development of Allergic Inflammation in a Mouse Model of Experimental Asthma
}

\author{
Stefanie Hagner ${ }^{\mathrm{a}}$ Carola Rask $^{c}$ Jens Brimnes ${ }^{c}$ Peter Sejer Andersen ${ }^{c}$ \\ Hartmann Raifer $^{\mathrm{b}}$ Harald Renz ${ }^{\mathrm{a}}$ Holger Garn ${ }^{\mathrm{a}}$

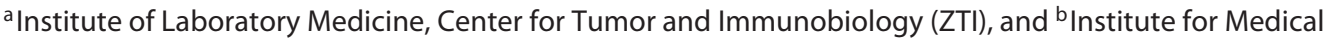 \\ Microbiology and Hospital Hygiene, Medical Faculty, Philipps University of Marburg, Marburg, Germany; \\ 'Immunology Department, ALK-Abelló, Horsholm, Denmark
}

\section{Key Words}

Allergen immunotherapy · Dermatophagoides farinae .

House dust mite $\cdot$ Sublingual

\begin{abstract}
Background: Evidence regarding sublingual immunotherapy (SLIT) efficacy and its good safety profile has been demonstrated with pollen and house dust mite (HDM) allergens in the treatment of airway allergies. In addition, the use of grass pollen presents a SLIT disease-modifying treatment for respiratory allergies. Objectives: The aim of this study was to demonstrate the efficacy of HDM-based SLIT in mouse models of allergic airway inflammation and to gain insights into the involved local immunological mechanisms. Methods: Balb/c mice were sensitized/challenged with Dermatophagoides farinae (Derf) extract and underwent Der f-SLIT in prophylactic and therapeutic settings. The SLIT efficacy was assessed using lung function measurements, analysis of local inflammatory responses by bronchoalveolar lavage cell differentiation and lung histology. Humoral and cellular responses were monitored by ELISA, cytokine bead array and flow cytometry analyses. Results: In a prophylactic setting,
\end{abstract}

Der f-SLIT with 12 development units per dose reduced the eosinophil-dominated inflammatory response in the lung paralleled by a marked reduction in airway hyperresponsiveness. Local Th2 responses were prevented as demonstrated by significantly lower levels of IL-5 and IL-13. Additionally, SLIT-treated mice revealed a lower proportion of CD4-CD8$\gamma \delta$ cells and a higher frequency of $C D 8+C D 25+I F N \gamma+T$ cells in the lungs compared to sham-treated mice. In a therapeutic setting, Der f-SLIT also resulted in reduced inflammatory responses in the lung. Conclusion: The efficacy of Der f-SLIT was demonstrated in prophylactic and therapeutic conditions using experimental mouse models of HDM-induced airway inflammation. A potential role of a so far underestimated lymphocyte subpopulation was also indicated.

(c) 2016 S. Karger AG, Basel

\section{Introduction}

Although there is currently much interest in developing causative asthma treatments targeting specific pathogenic effector pathways, guideline-based anti-inflammatory treatment still remains symptomatic. However, al-

\section{KARGER}

E-Mail karger@karger.com

www.karger.com/iaa (c) 2016 S. Karger AG, Basel

$1018-2438 / 16 / 1701-0022 \$ 39.50 / 0$
Correspondence to: Prof. Dr. Holger Garn

Institute of Laboratory Medicine, Center for Tumor and Immunobiology (ZTI)

Medical Faculty, Philipps University of Marburg

Hans-Meerwein-Strasse 3, DE-35043 Marburg (Germany)

E-Mail garn@staff.uni-marburg.de 
lergen-specific immunotherapy (AIT), involving the repeated administration of the allergens by subcutaneous injection (SCIT) or the mucosal route, has now emerged as the first etiologic-based treatment of allergic asthma by enhancing immune tolerance mechanisms [1]. Allergen administration via the oral mucosa route, such as sublingual immunotherapy (SLIT), represents an alternative application strategy to conventional SCIT. The advantage of SLIT in comparison to SCIT is the reduced risk of severe systemic adverse events and the convenience of selfadministration at home. The efficacy of SLIT in patients with allergic rhinitis and asthma has been demonstrated in several clinical studies [2-11] and there are four SLITtablets approved as medicinal products worldwide GRAZAX $^{\circledR}$ and Oralair (both grass) in Europe, Ragwitek (ragweed) in the USA and Actair (house dust mite; HDM) in Japan. These studies were conducted in patients already suffering from allergic diseases. In addition, there are also studies suggesting that subcutaneous AIT may prevent the development of asthma [12-14], although this observation needs further verification in order to be established firmly. A clinical trial aiming to assess whether SLIT with grass tablets is able to prevent the development of asthma in children with allergic rhinitis is ongoing [15].

Although the immune tolerogenic processes of the oral mucosa may contribute greatly to the therapeutic mechanisms of SLIT [16], there is still a knowledge gap concerning the underlying mechanism of action of SLIT, especially with regard to protective mechanisms in the main disease target organ, i.e. the lung. Animal models representing key features of asthma may provide important insights into the underlying mechanisms of SLIT. In the current study, we validated the efficacy of SLIT with HDM extract in a prophylactic (preventive) as well therapeutic setting, with focus on revealing the contribution of adaptive immune processes.

\section{Material and Methods}

\section{Animals and Extracts}

Female Balb/c mice (6-8 weeks old) were housed in pathogenfree facilities with individually ventilated cages with free access to water and chow. All animal experiments were approved by the responsible local authorities, i.e. Regierungspräsidium Giessen (Germany) and Dyreforsøgstilsynet (Denmark).

Allergic inflammation and airway hyperreactivity (AHR) were induced in the mice by exposure to standardized allergen extracts derived from whole-mite cultures of Dermatophagoides farinae (Der f; ALK-Abelló A/S, Horsholm, Denmark). The extracts were standardized against an in-house reference. The units are ex- pressed in development units (DU) [17], with 1 DU of the research-grade batch of Der f extract used in the present study corresponding to $3.4 \mu \mathrm{g}$ of Der $\mathrm{f} 1$ and $1.4 \mu \mathrm{g}$ of Der f 2 , respectively. The LPS content was measured to be $26.7 \mathrm{EU} / \mu \mathrm{g}$ of dry matter.

\section{Experimental Design}

Prophylactic Model

Mice $(n=8)$ were sensitized by two intraperitoneal (i.p.) injections of 0.5 DU Der f extract adsorbed to Alhydrogel (Brenntag Biosector, Fredrikssund, Denmark) on days 0 and 14. On days 2124 , all mice were challenged intranasally (i.n.) with 0.5 DU Der $f$ extract in $25 \mu \mathrm{l}$ of phosphate-buffered serum (PBS). AHR was assessed by whole-body plethysmography on day 24 . The mice were sacrificed on day 25 and all other analyses were performed. Mice were SLIT treated on 5 subsequent days per week for 2 weeks with either 3 or $12 \mathrm{DU}$ of Der f extract or PBS as the sham control prior to the i.p. injections (fig. 1a).

In an alternative protocol, mice $(\mathrm{n}=16)$ were i.n. sensitized/ challenged with 1.5 DU of Der f extract (or PBS as a control) once a week a total of four times. The mice were sacrificed and analyses were performed. SLIT was performed in advance of the first i.n. application with 12.6 DU of Der f extract or PBS as a control three times per week for 4 weeks (fig. 1b).

\section{Therapeutic Model}

Mice $(n=16)$ were i.n. sensitized/challenged with 1.5 DU of Der f extract (or PBS as a control) once a week a total of four times and additionally challenged on days 52 and 53 of the protocol. The mice were sacrificed on day 55 and analyses were performed. SLIT was performed with 12.6 DU of Der f extract or PBS as a control three times per week for 4 weeks starting after the fourth i.n. Der $f$ extract application (fig. 1c).

\section{SLIT Treatment}

For SLIT treatment, $5 \mu \mathrm{l}$ of Der $\mathrm{f}$ extract solution at different doses was applied under the tongue. The mice were held by their scruffs for 20 s to prevent the animals from immediately swallowing the solution.

\section{Analysis of Allergen-Specific Immunoglobulins}

ELISA Assay

For the detection of Der f-specific IgE, IgG1, IgG2a and IgA, plates were coated with Der $\mathrm{f}$ extract (at doses equivalent to 1.5 $\mathrm{DU} / \mathrm{ml}$ ) in bicarbonate buffer ( $\mathrm{pH} 9.6$ ) overnight at $4^{\circ} \mathrm{C}$. Subsequently, coated wells were blocked with $1 \% \mathrm{w} / \mathrm{v}$ bovine serum albumin in PBS for $2 \mathrm{~h}$ at room temperature. After washing, serum samples (1:10) were incubated overnight at $4^{\circ} \mathrm{C}$, washed and incubated with the respective isotype-specific biotin-labeled anti-Ig antibody overnight at $4^{\circ} \mathrm{C}$. Plates were washed and incubated with streptavidin peroxidase for $30 \mathrm{~min}$ at room temperature. After development with $\mathrm{BM}$ Blue POD substrate the reaction was stopped using $\mathrm{H}_{2} \mathrm{SO}_{4}$ and ODs were read at $450 \mathrm{~nm}$.

\section{Magic Lite Assay}

Serum Der f-specific IgE antibodies were also determined by Magic Lite assay [18]. Briefly, sera were diluted in wash buffer ( $0.06 \%$ gelatin and $0.1 \%$ Triton $\mathrm{X}$ in PBS, $\mathrm{pH}$ 6.65) and incubated with magnetic-coupled particles to goat anti-mouse IgE (Indicia Biotechnology, Qullins, France). After washing, Der f-specific antibodies were detected by biotinylated Der f extract and streptavi- 
Fig. 1. Experimental design. a Prophylactic model: female Balb/c mice were sensitized by two i.p. injections of 0.5 DU Der f adsorbed to Alhydrogel on day (d) 0 and 14 to induce an allergic airway inflammation. Mice were challenged i.n. with $0.5 \mathrm{DU}$ of Der f extract. Before sensitization, the mice were sublingually treated with two different doses Der f extract (or PBS as a control). AHR was assessed by whole-body plethysmography. $\mathbf{b}$ For the induction of an allergic airway response, the mice were i.n. exposed to 1.5 DU of Der f extract (or PBS as a control) once a week and four times altogether. Before sensitization, the mice were sublingually treated with 12.6 DU of Der $\mathrm{f}$ extract (or PBS as a control) for 4 weeks. c Therapeutic model: mice were i.n. exposed to 1.5 DU of Der f extract (or PBS as a control) once a week and four times altogether. The mice were then treated sublingually with 12.6 DU of Der f extract (or PBS as a control) for 4 weeks and then rechallenged twice with 1.5 DU of Der f extract.

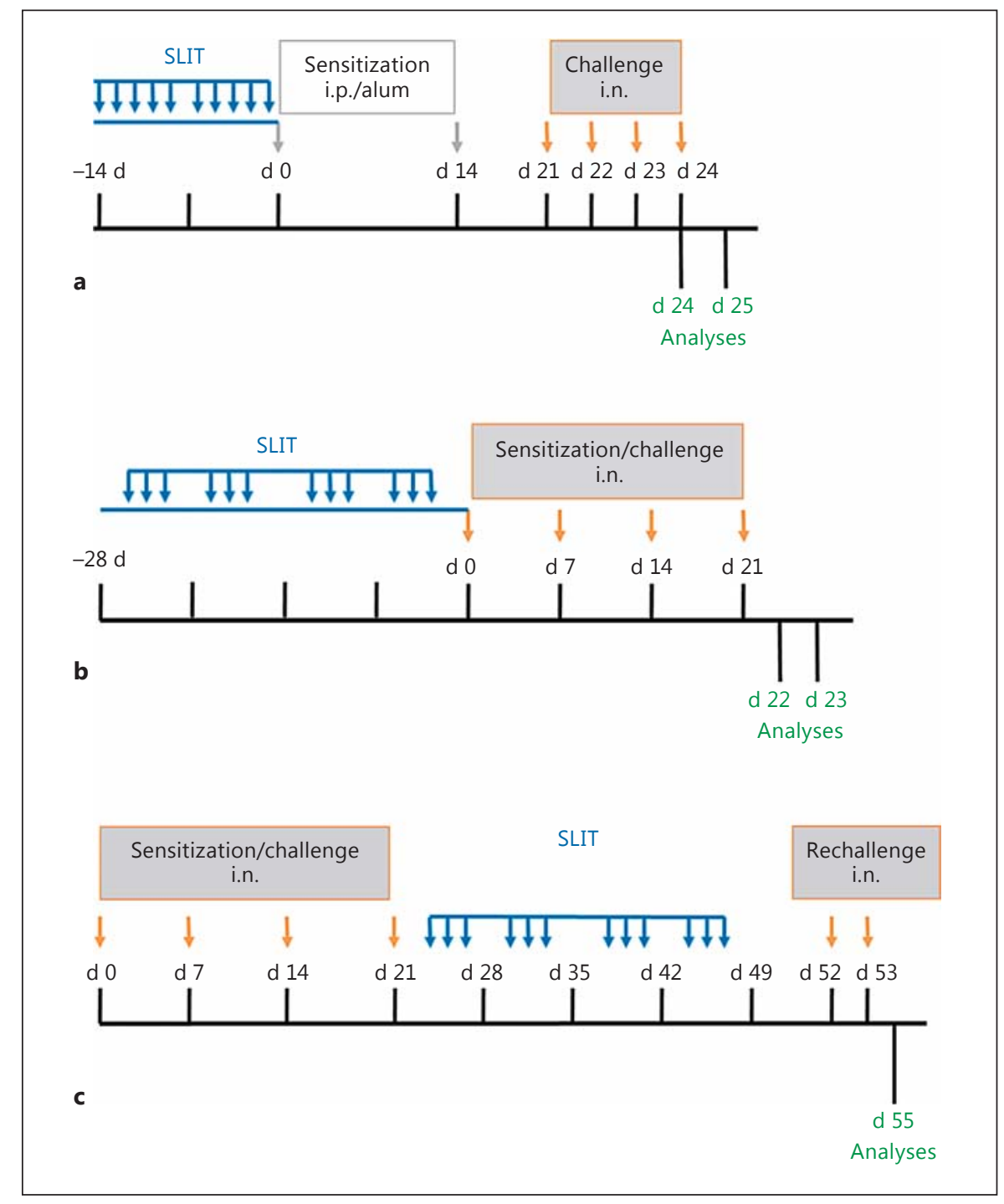

din conjugated to acridinium ester. Quantification was carried out in the Automat Plus LB953 (Berthold Technologies, Bad Wildbad, Germany) with automated injection of peroxide and hydrochloride acid.

\section{Bronchoalveolar Lavage and Differential Cell Counts}

Using a tracheal cannula, bronchoalveolar lavage (BAL) was performed with $1 \mathrm{ml}$ of PBS containing a protease inhibitor cocktail (Roche, Basel, Switzerland). Total leukocytes were counted with an automated cell counter (Casy TT; Schaerfe Systems, Reutlingen, Germany) and cell-free supernatant was stored at $-20^{\circ} \mathrm{C}$ for cytokine measurements. Cells were resuspended in PBS (with $1 \%$ bovine serum albumin) and cytospins were prepared and subsequently Diff-Quick (Merz \& Dade AG, Düdingen, Germany) stained. Differential cell counts were obtained by microscopic evaluation of inflammatory cell types (eosinophils, lymphocytes, macrophages, neutrophils) according to typical morphological criteria.

\section{Restimulation of Lymph Node Cells}

Single cell suspensions of mediastinal lymph node cells were generated by filtering through a $100-\mu \mathrm{m}$ cell strainer, washing and suspending in RPMI medium with $10 \%$ fetal calf serum (FCS). Lymph node cells were seeded in 96-wells at $2 \times 10^{6} / \mathrm{ml}$ and stimulated with or without Der f extract (at doses equivalent to $3 \mathrm{DU} /$ $\mathrm{ml})$ for 5 days.

\section{Cytokine Measurements}

IL-5, IL-13, IL-17, IL-10 and IFN $\gamma$ in cell-free supernatants from restimulated lymph node cells were measured by Cytometric Bead Array (Becton Dickinson, Heidelberg, Germany) using FACSArray.

\section{Lung Histology}

Lung tissues were removed and fixed in $6 \%$ paraformaldehyde for $24 \mathrm{~h}$. The lungs were then embedded in $2 \%$ agarose, $5 \mu \mathrm{m}$ transverse sections were prepared using a microtome and stained with hematoxylin and eosin or periodic acid/Schiff-staining. Specimens 
were microscopically evaluated with focus on peribronchial and perivascular inflammatory cell infiltration and goblet cell hyperplasia. The inflammation score was assessed as described [19]. The number of goblet cells in the bronchial epithelium was quantified and expressed as the average cell number per millimeter of basement membrane.

\section{Penh Measurement}

AHR was measured in vivo $24 \mathrm{~h}$ after the fourth i.n. challenge using whole-body plethysmography (EMKA Technologies, Paris, France) by challenging the mice with increasing concentrations of aerosolized methacholine (0-25 mg/ml; Sigma Aldrich, St. Louis, Mo., USA). AHR was measured as increases in enhanced pause (Penh), as an arbitrary indicator for airway obstruction [20]. Mice were challenged with methacholine for $2 \mathrm{~min}$, followed by $6 \mathrm{~min}$ of data recording.

\section{Airway Resistance}

Lung resistance was measured $24 \mathrm{~h}$ after the last allergen challenge in response to increasing doses of methacholine $(2.5-50 \mathrm{mg} /$ $\mathrm{ml}$ ) in tracheostomized anesthetized mice using the flexiVent animal mechanical ventilator system (Scirec Inc., Montreal, Que., Canada). Mechanical ventilation was set at 150 breaths/min with a tidal volume of $0.16 \mathrm{ml} / \mathrm{kg}$ and a positive end-expiratory pressure of $3 \mathrm{~cm} \mathrm{H}_{2} \mathrm{O}$.

\section{Flow Cytometry}

Perfused lungs were cut into 2 - to 5 - $\mathrm{mm}$ pieces and incubated for $30 \mathrm{~min}$ at $37^{\circ} \mathrm{C}$ in the incubation medium [IM; RPMI-1640 with L-Glutamine and $\mathrm{NaHCO}_{3}, 10 \%$ FCS, $1 \times$ nonessential amino acids (PAA, Pasching, Austria), $100 \mu \mathrm{g} / \mathrm{ml}$ streptomycin, $120 \mu \mathrm{g} / \mathrm{ml}$ penicillin] supplemented with $1 \mathrm{mg} / \mathrm{ml}$ Collagenase D (Roche) and 20 $\mu \mathrm{g} / \mathrm{ml}$ DNase I (Roche). Predigested lungs were minced through $100-\mu \mathrm{m}$ nylon cell strainers (BD Falcon, Franklin Lakes, N.J., USA) diluted with IM and centrifuged at 1,700 rpm for $5 \mathrm{~min}$. Cell pellets were resuspended in erythrocyte lysis buffer $\left(8 \mathrm{~g} / \mathrm{l} \mathrm{NH} \mathrm{NH}_{4}\right.$; $1 \mathrm{~g} / \mathrm{l}$ $\mathrm{KHCO}_{3} ; 37.2 \mathrm{mg} / \mathrm{l} \mathrm{EDTA}$ ) and incubated at room temperature for 3-5 min. Then, cells were washed with IM, centrifuged and resuspended in IM supplemented with $50 \mathrm{ng} / \mathrm{ml} \mathrm{PMA,} 750 \mathrm{ng} / \mathrm{ml}$ ionomycin and $10 \mathrm{mg} / \mathrm{ml}$ brefeldin A for $4 \mathrm{~h}$. T cell surface marker staining was performed in PBS with 1\% FCS and the presence of Fc Block anti-CD16/CD32 (Becton Dickinson). The following fluorophorelabeled antibodies were used: anti-CD4-V450 (Becton Dickinson), anti-CD25-PE-Cy7, anti-CD8-V50 (Becton Dickinson) and anti$\gamma \delta$-T cell receptor (eBioscience, San Diego, Calif., USA). After extracellular staining, $\mathrm{T}$ cells were fixed with FoxP3-Fixation Kit (eBioscience) and permeabilized with $0.3 \%$ saponin, $1 \%$ FCS in PBS followed by an intracellular staining in the presence of BD Fc Block anti-CD16/CD32 (Becton Dickinson) with the following fluorophore-labelled antibodies: IFN $\gamma$-PerCP-Cy5.5 (Biolegend, San Diego, Calif., USA) FoxP3-Alexa Fluor 700; IL-5-PE; IL-10-APC. Every staining included respective negative and isotype controls. Fluorescence signals were acquired by flow cytometry (FACSAria III; Becton Dickinson) and analyzed using FACSDiva ${ }^{\mathrm{TM}}$ software.

\section{Statistical Analyses}

Data analyses were performed using GraphPad Prism version 5.01 (GraphPad Software Inc., San Diego, Calif., USA). All statistical calculations were performed using one-way ANOVA and Tukey analysis. Differences were considered significant at $\mathrm{p}<0.05$.

\section{Results}

Efficacy of SLIT in Prophylactic Treatment Models

For an initial proof-of-concept and for dose finding purposes, the efficacy of SLIT was tested in a standard model of allergic airway inflammation in mice using i.p. sensitization in the presence of adjuvant and subsequent airway challenge with Der $\mathrm{f}$ extract as outlined in figure 1a. The phenotype of this model is characterized by an almost exclusively Th2-driven- eosinophil-dominated airway inflammation with characteristic features that include eosinophil infiltration in BAL, increase in Th2 cytokines, and increase in allergen-specific IgE antibodies, as well as increased AHR to methacholine. As shown in figure 2a, fewer leukocytes and eosinophils were found in the BAL of SLIT-treated mice compared to sham-treated controls. Additionally, there were significantly lower levels of the Th2 cytokines IL-5 and IL-13 (fig. 2b) in the supernatants of Der f extract restimulated lymph node cells and reduced Der f-specific IgE levels in the serum (fig. 2c) of SLIT-treated mice (at both doses of sublingual Der $\mathrm{f}$ ) than in sham-treated mice. Furthermore, SLIT-treated mice exhibited a lower degree of AHR to metacholine as compared to controls as determined by in vivo measurements of airway reactivity (fig. 2d).

These observations were confirmed in a more clinically relevant model using the natural route of allergen exposure in which the development of allergic airway inflammation was achieved by an adjuvant-free local (i.n.) sensitization and challenge regimen, as shown in figure $1 b$. The phenotype of this model is characterized by a more mixed (eosinophil/neutrophil) inflammation in contrast to sensitization by i.p. administration of allergen with alum. Also, under these conditions, SLIT treatment resulted in significantly lower leukocyte numbers in the BAL, mainly due to a reduction in eosinophils and neutrophils, but also lymphocyte numbers (fig. 3a). Histological evaluation of the lungs (fig. 3b) revealed a signifi-

Fig. 2. Prophylactic SLIT with Der f extract is efficacious in a dosedependent manner. Balb/c mice were sensitized and challenged after receiving prophylactic SLIT according to figure 1a. a Total cell numbers and numbers of eosinophils in BAL. b IL-5 and IL13 cytokine levels in supernatants of restimulated lymph node cells. c Serum Der f-specific immunoglobulins of the IgE isotype. $\mathrm{RLU}=$ relative light units. $\mathbf{d}$ AHR to methacholine was measured by whole-body plethysmography and expressed as the Penh index. $\mathrm{n}=8$ mice per group. ${ }^{*} \mathrm{p} \leq 0.05$ versus the allergic sham-treated group.

(For figure see next page.)

Int Arch Allergy Immunol 2016;170:22-34 
Leukocytes

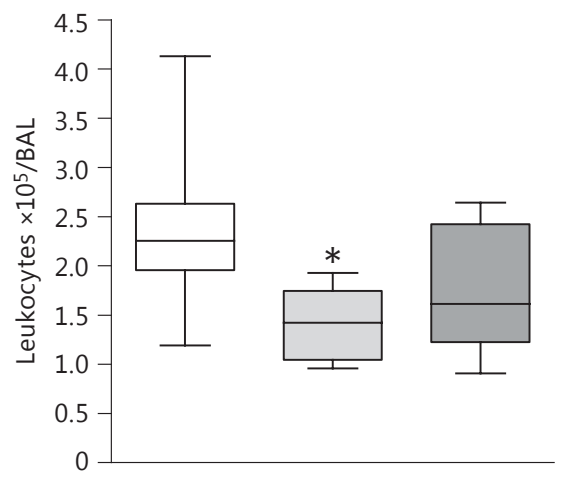

\begin{tabular}{|c|c|c|c|}
\hline SLIT & PBS & 3 DU Der $\mathrm{f}$ & 12.6 DU Der $\mathrm{f}$ \\
\hline Challenge & Der $\mathrm{f}$ & Der $\mathrm{f}$ & Der $\mathrm{f}$ \\
\hline
\end{tabular}

IL-5

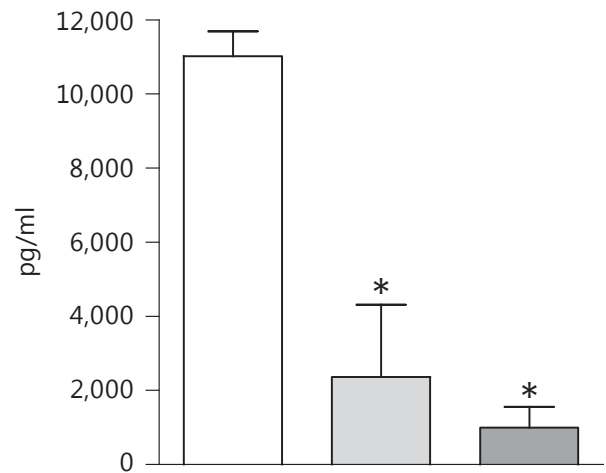

b

\begin{tabular}{|c|c|c|c|}
\hline SLIT & PBS & 3 DU Der $\mathrm{f}$ & 12 DU Der $\mathrm{f}$ \\
\hline Challenge & Der $\mathrm{f}$ & Der $\mathrm{f}$ & Der $\mathrm{f}$ \\
\hline
\end{tabular}

Eosinophils

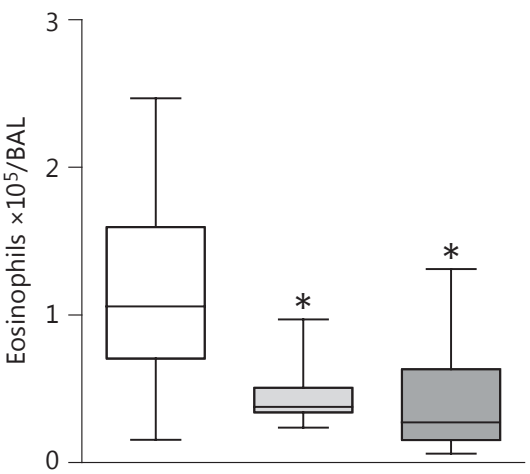

\begin{tabular}{|c|c|c|c|}
\hline SLIT & PBS & 3 DU Der $\mathrm{f}$ & 12 DU Der $\mathrm{f}$ \\
\hline Challenge & Der $\mathrm{f}$ & Der $\mathrm{f}$ & Der $\mathrm{f}$ \\
\hline
\end{tabular}

IL-13

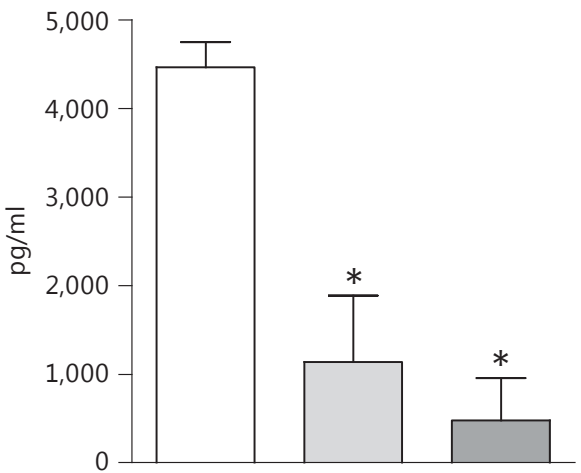

\begin{tabular}{|c|c|c|c|}
\hline SLIT & PBS & 3 DU Der $\mathrm{f}$ & 12 DU Der $\mathrm{f}$ \\
\hline Challenge & Der $\mathrm{f}$ & Der $\mathrm{f}$ & Der $\mathrm{f}$ \\
\hline
\end{tabular}

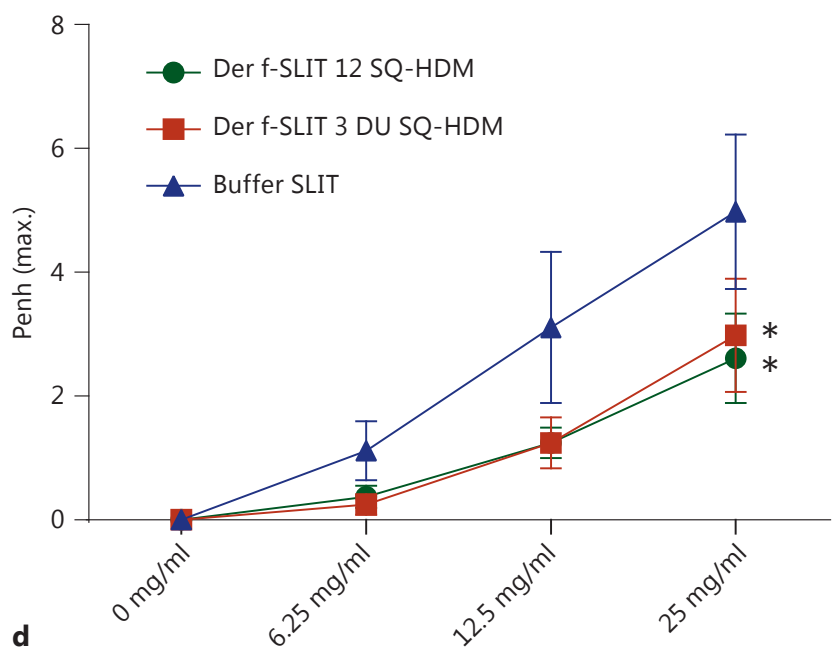

2

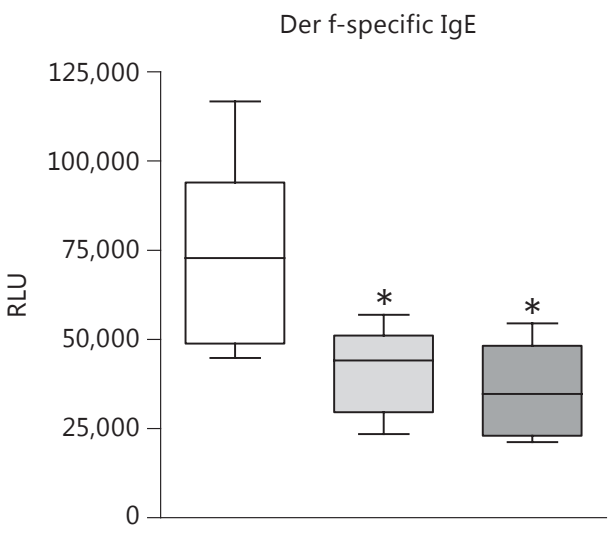

c

\begin{tabular}{|c|c|c|c|}
\hline SLIT & PBS & 3 DU Der $\mathrm{f}$ & 12 DU Der $\mathrm{f}$ \\
\hline Challenge & Der $\mathrm{f}$ & Der $\mathrm{f}$ & Der $\mathrm{f}$ \\
\hline
\end{tabular}


Fig. 3. a, b Efficacy of prophylactic SLIT with Der f extract. Balb/c mice were sensitized and challenged after receiving prophylactic SLIT according to figure $1 \mathrm{~b}$. a Total cell numbers and differential cell numbers in the BAL. $\mathbf{b}$ Representative photomicrographs of lung histology. Original magnification $\times 200 . \mathrm{n}=16$ mice per group ${ }^{*} \mathrm{p} \leq 0.05$ and ${ }^{* *} \mathrm{p} \leq 0.01$ versus the allergic sham-treated group.
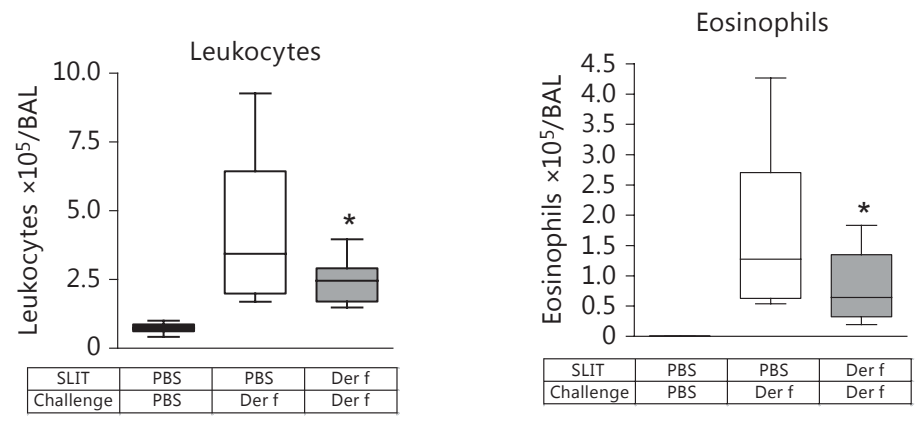

a
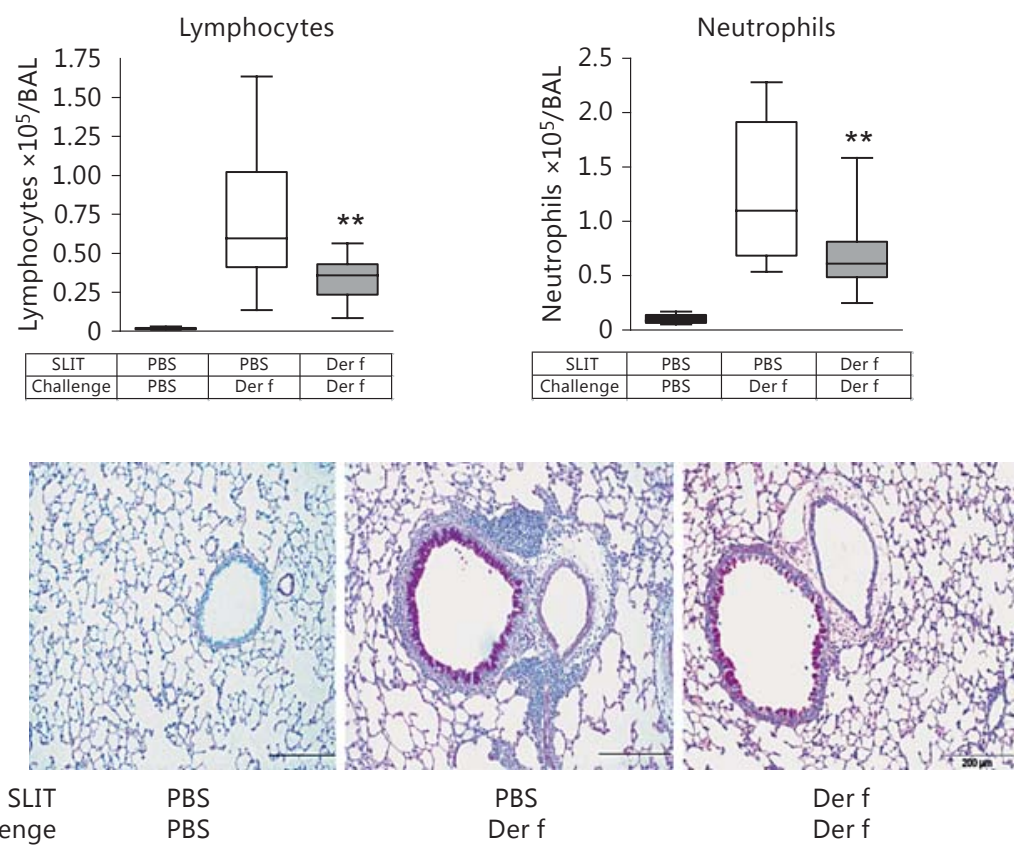

b Challenge
PBS
Der $f$ cantly reduced peribronchial cellular infiltrate paralleled by a trend to lower numbers of mucus-producing goblet cells (fig. 3c) in SLIT-treated mice compared to shamtreated controls. The measurement of serum levels of Der f-specific IgG1 and IgG2a revealed no significant differences between SLIT-treated and control mice (fig. 3d), while Der f-specific IgE was not detectable (data not shown). BAL levels of IgA showed a tendency for increase in SLIT-treated mice in comparison to sham-treated mice, but without reaching statistical significance. Invasive lung function measurements revealed increased resistance in the allergic sham-treated group whereas a significant reduction in pulmonary resistance in SLIT-treated mice in comparison to the control group was observed (fig. 3e).

\section{Effect of SLIT on Local T Cell Differentiation and Activation}

Since the inflammatory response in the airways is regulated to a large extent by T cells, further mechanistic studies were performed to identify lung $\mathrm{T}$ cell subpopulations following SLIT. Therefore, T cells from lung homogenates were analyzed by flow cytometry. In SLIT-treated compared to sham-treated mice, there was no difference in the CD4+/CD8+ T cell ratio (fig. 4a, grey bar). In contrast, the proportion of CD4-CD8 $-\gamma \delta$ T cells was significantly lower in SLIT-treated mice compared to sham-treated controls (fig. 4b, grey bar), while a nonsignificant trend for an increased proportion of lung CD4+ T cells positive for Foxp3 and CD25 (fig. 4c, grey bar) was observed. To further characterize the effects of SLIT on the phenotype of 
Fig. 3. c-e Efficacy of prophylactic SLIT with Der f extract. Balb/c mice were sensitized and challenged after receiving prophylactic SLIT according to figure $1 \mathrm{~b}$. c Quantification of inflammation and mucus-producing goblet cells in the airways of mice. $\mathrm{BM}=$ Basal membrane. $\mathbf{d}$ Serum levels of Der f-specific IgG1, IgG2a and BAL IgA. The OD (450 nm)-Blank of the respective immunoglobulins is shown. e Airway resistance values in response to increasing concentrations of metacholine (Mch). $\mathrm{n}=$ 16 mice per group ${ }^{*} p \leq 0.05$ and ${ }^{* *} p \leq 0.01$ versus the allergic sham-treated group.

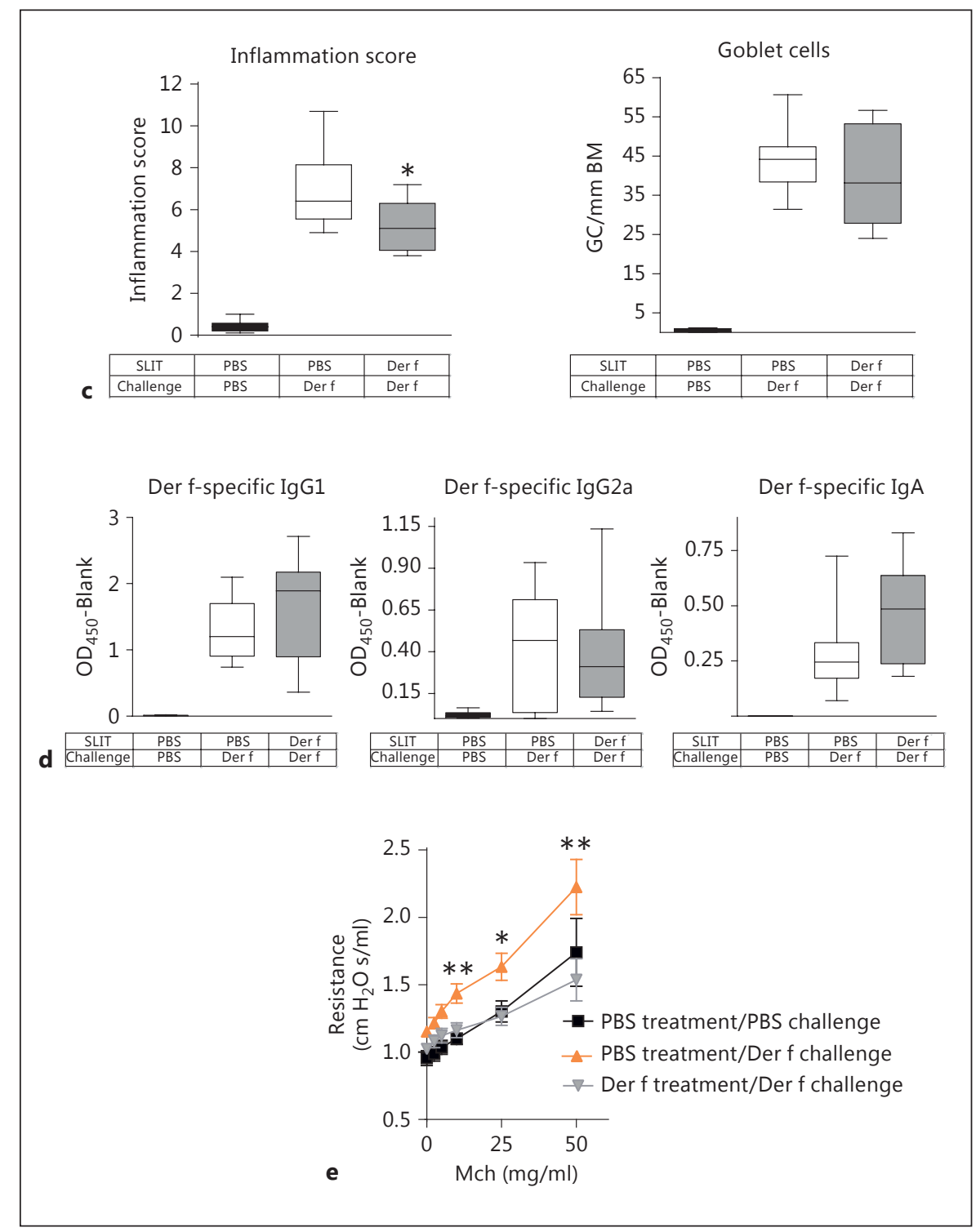

lung $\mathrm{T}$ cell subpopulations, lung CD4+ and CD8+ T cells were stimulated ex vivo with PMA and ionomycin before performing intracellular cytokine staining for IL-5, IFN $\gamma$ and IL-10. The frequency of IL-5+ cells among CD4+ CD25+ T cells from SLIT-treated mice (fig. 4d, left, grey bar) was significantly lower compared to T cells from sham-treated mice. While the frequency of IFN $\gamma+$ cells were similar (fig. 4d, middle, grey bar), the frequency of IL-10+ cells (fig. 4d, right, grey bar) was slightly but nonsignificantly higher in SLIT-treated animals. In contrast, the frequency of CD $8+\mathrm{CD} 25+\mathrm{IFN} \gamma+$ cells was significantly higher in cells from SLIT-treated mice (fig. 4e, middle, grey bar). The frequencies of CD8+CD25+IL-5+ (fig. 4e, left, grey bar) and of CD8+CD25+IL-10+ cells (fig. 4e, right, grey bar) were generally low and not different between cells from the SLIT- and sham-treated allergic groups.

Analyses of cytokine levels in the supernatants of Der f restimulated lymph node cells revealed significantly lower levels of the Th2 cytokines IL-5 and IL-13, the Th17 cytokine IL-17 and the Treg cytokine IL-10 (fig. 5, grey bars) following SLIT compared to sham treatment. Concentrations of the Th1 cytokine IFN $\gamma$ remained below the detection limit in both groups. BALF levels of IL-13 were significantly lower in SLIT-treated mice in comparison to the sham-treated mice (data not shown); all other cytokines (IL-5, IL-17, IL-10) were not detectable. 


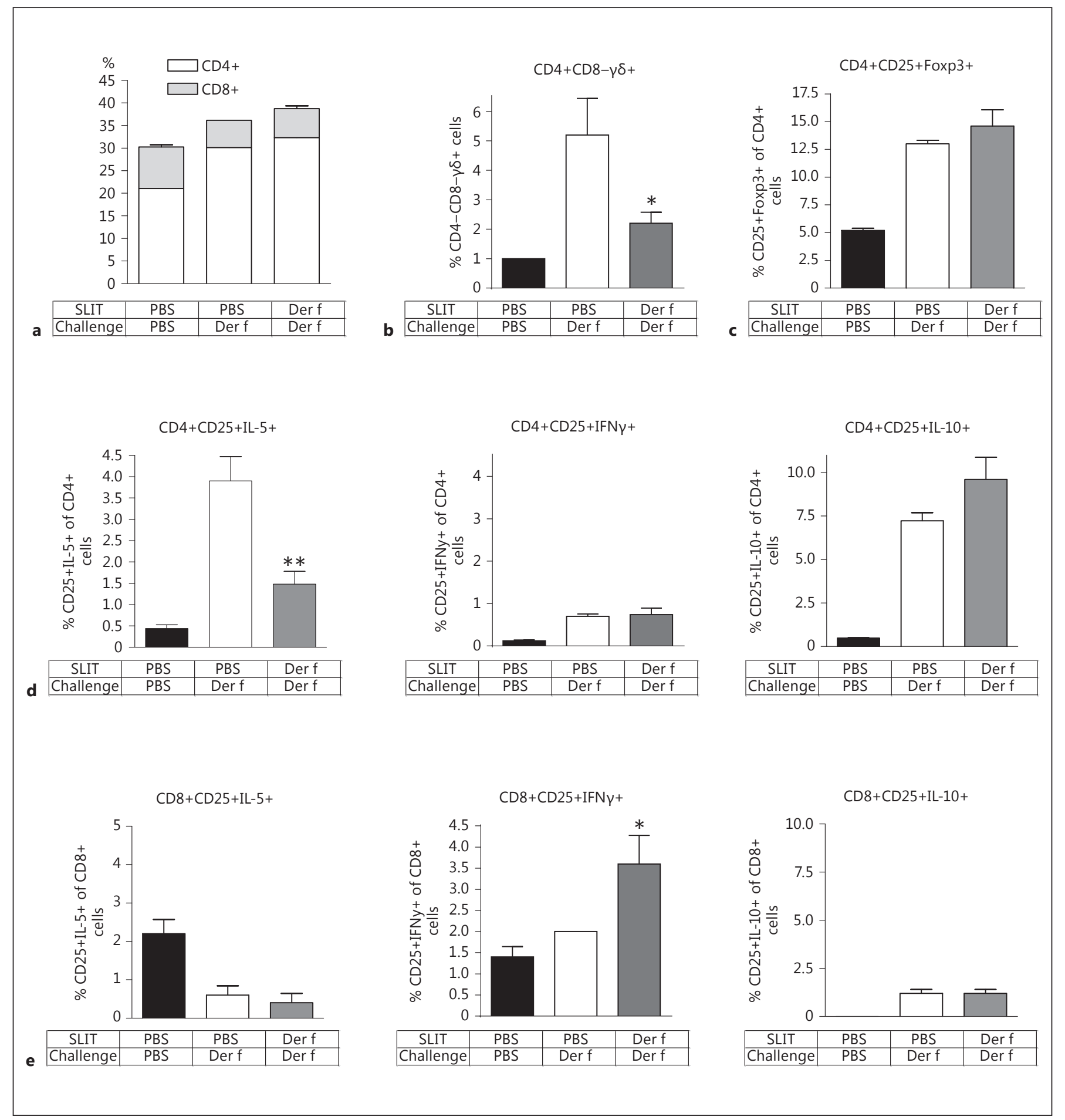

Fig. 4. Flow cytometric analysis of $\mathrm{T}$ cells from lung tissue. $\mathrm{T}$ cells were measured by flow cytometry from the homogenized lungs of PBS- and Der f extract-treated animals according to the experimental protocol. a Ratio of CD4+ and CD8+ T cells. b Percentages of $\gamma \delta+$ cells among CD4-CD8 - cells. c Percentages of FoxP3+ cells among CD4+CD25+ cells. $\mathbf{d}$ Percentages of IL-5+, IFN $\gamma+$ and IL-10+ cells among CD4+CD25+ cells. e Percentages of IL-5+, IFN $\gamma+$ and IL- $10+$ cells among CD8+CD25+ cells. The means \pm SEMs of 8 mice per group are shown. ${ }^{*} \mathrm{p} \leq 0.05$ and ${ }^{* *} \mathrm{p} \leq 0.01$ versus the allergic sham-treated group. 
Fig. 5. Modulation of the cytokine profile. IL-5, IL-13, IL-17 and IL-10 cytokine concentrations in restimulated mediastinal lymph node cells. The means \pm SEMs of 8 mice per group are shown. ${ }^{*} \mathrm{p} \leq 0.05$ versus the allergic sham-treated group.

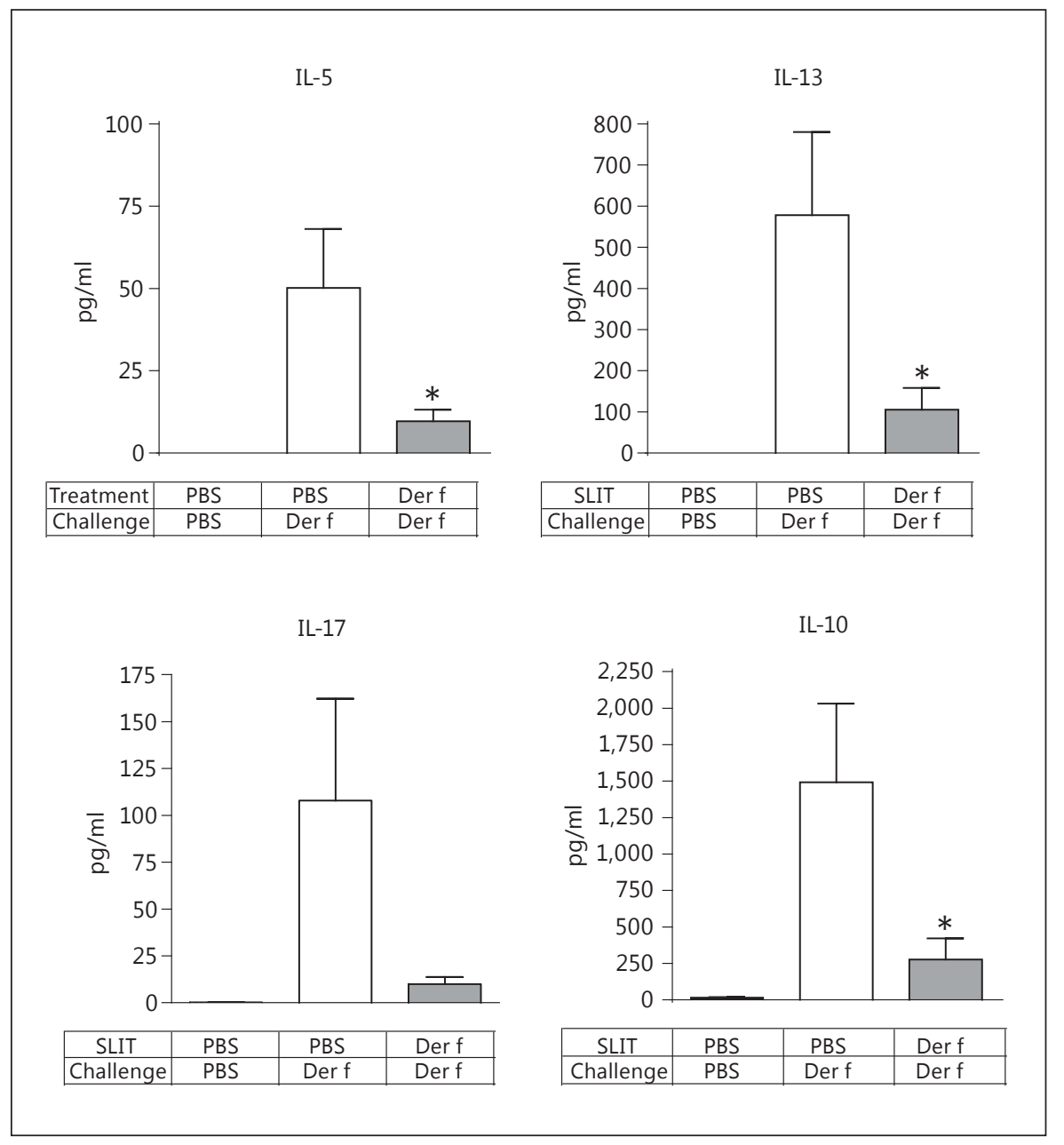

\section{Efficacy of SLIT in a Therapeutic Treatment Model}

The therapeutic efficacy of SLIT was investigated in the model using the natural route of allergen exposure for the induction of HDM-induced allergic airway inflammation. Mice were SLIT treated three times per week starting at a time point when an allergic airway inflammation had already been established. Mice were rechallenged i.n. after the SLIT treatment, as outlined in figure 1c. We observed a less pronounced inflammatory response in the BAL of the allergic sham-treated mice in comparison to the previous models. However, as shown in figure 6a, histological analysis of lung tissue clearly indicated reduced peribronchial and perivascular inflammatory infiltrations in the lungs of SLIT-treated mice in comparison with sham-treated controls. This observation was substantiated by a significantly lower inflammation score and a tendency towards lower numbers of mucus-producing goblet cells (fig. 6b). Total BAL cell numbers were similar in the BALs of SLIT- and sham-treated mice (fig. 6c). As indicated in figure 6d, there were no significant differences between serum levels of IgG1 and IgG2a, while slightly yet nonsignificantly increased BAL IgA levels were observed in SLIT-treated mice (fig. 6d).

\section{Discussion}

SLIT is established as a safe and efficient approach to inducing antigen-specific immunological tolerance and is thus increasingly applied as a causative treatment option for type I respiratory allergies against grass, ragweed and HDM allergies in humans [2-11]. With respect to the immune mechanisms underlying the effect of SLIT, the current hypothesis dictates that the allergen is rapidly captured by oral tolerogenic dendritic cells that subsequently migrate to cervical lymph nodes where Th2- 


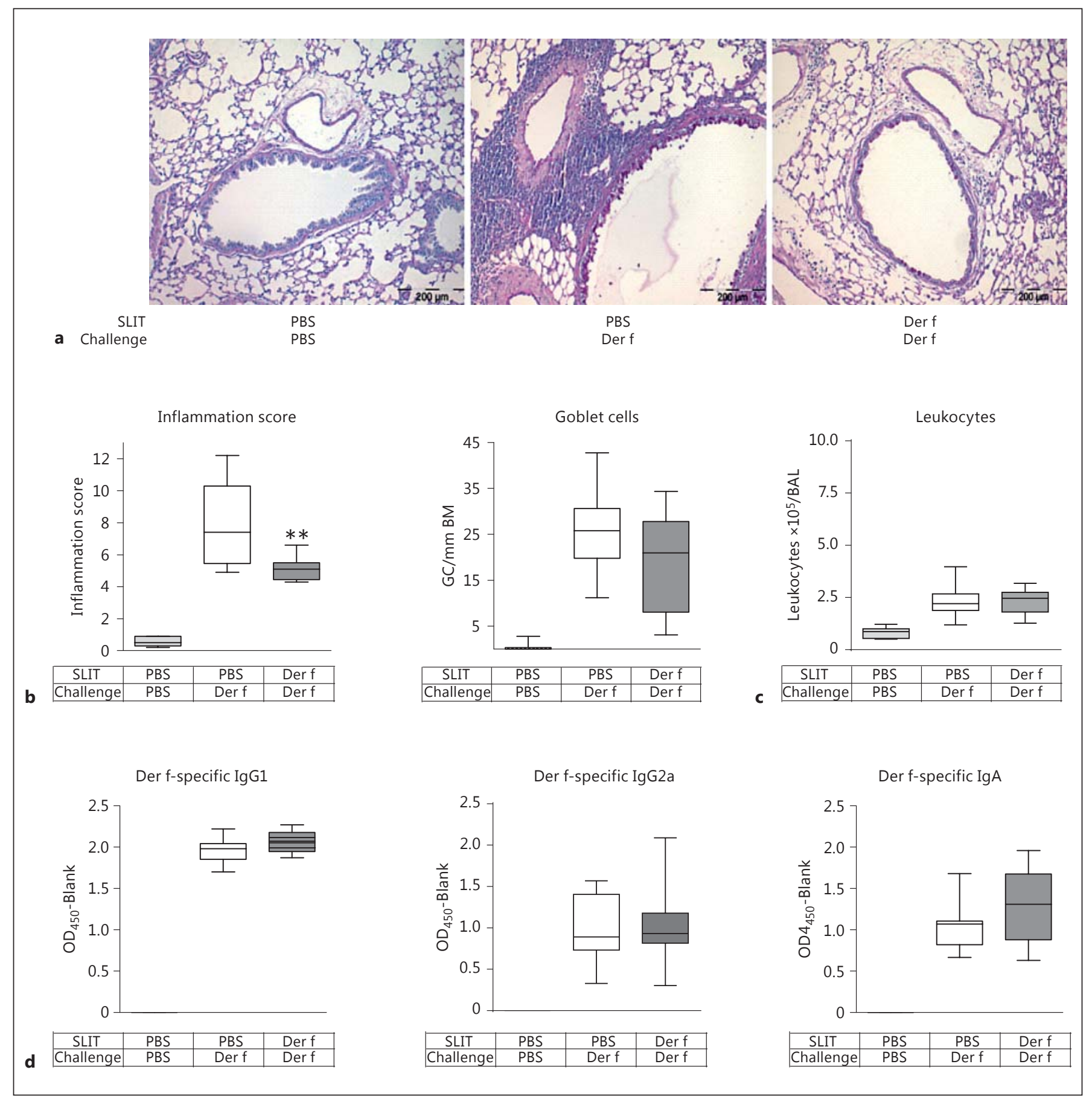

Fig. 6. Efficacy of therapeutic SLIT with Der f extract. Balb/c mice were sensitized and challenged after receiving therapeutic SLIT according to figure 1c. a Representative photomicrographs of lung histology. Original magnification $\times 200$. b Quantification of inflammation and mucus-producing goblet cells in the airways of mice. $\mathrm{BM}=$ Basal membrane. $\mathbf{c}$ Total cell numbers and differential cell numbers in the BAL. d Serum Der f-specific immunoglobulins of the isotypes IgG1, IgG2a and BAL IgA. The OD (450 nm)-Blank of the respective immunoglobulins is shown. $\mathrm{n}=16$ mice per group. ${ }^{* *} \mathrm{p} \leq 0.01$ versus the allergic sham-treated group. 
counteracting Th1/Treg responses are induced. SLIT has been shown to elicit allergen-specific IFN $\gamma$ - and IL-10-secreting CD4+ T cells in peripheral blood as well as increased numbers of Foxp3+ Tregs in the oral tissue [16, 21 . Although such systemic and oral mucosal changes in CD4+ T cell responses certainly correlate with immune tolerance induction during SLIT, tissue events and mechanisms at the site of the ongoing inflammatory process are not well understood since they are difficult to investigate in human patients. Thus, the present study was performed to: (i) evaluate the efficacy of SLIT treatment with a Der f extract in mouse models of allergic airway inflammation, and (ii) gain more insight into the local tissue events that occur during SLIT at the site of disease manifestation. Therefore, prophylactic as well as therapeutic mouse models were applied in order to assess the efficacy and mode of action of SLIT on parameters of the allergic phenotype.

Initially, we applied a model with adjuvant-supported systemic sensitization resulting in a strong Th2-driven and eosinophil-dominated phenotype of allergic airway inflammation following allergen challenge via the airways to demonstrate the efficacy of SLIT with the HDMderived allergen Der $\mathrm{f}$. We observed a dose-dependent effect of Der f-SLIT in reducing the development of the asthmatic phenotype as indicated by a significant reduction in AHR, eosinophil infiltrates in BAL and Th2 immune responses. These results are consistent with findings from other studies conducted in a comparable prophylactic setting in mice, involving allergens like ovalbumin, Phleum pratense and rBet v 1, as well as Der $\mathrm{f}$ [22-25].

Using the most efficacious allergen dose from these initial investigations, we subsequently tested Der f-SLIT in a more clinically relevant model that better resembles the human allergen exposure mainly in the sensitization process (i.e. absence of adjuvants, natural route of allergen exposure exclusively via the airways by i.n. application). Comparable to the human situation and in accordance with previous observations $[26,27]$, this model resulted in a mixed inflammatory response in the airways with concomitant infiltration of eosinophils and neutrophils. Investigating the efficacy of SLIT for the first time in this clinically relevant model, we were able to demonstrate similar treatment effects on parameters such as AHR, eosinophil infiltrates in BAL and Th2 responses as observed in systemically sensitized animals. In addition, BAL neutrophil numbers were also significantly reduced following Der f-SLIT in this model. With respect to the various endotypes described recently for asthma defining distinct pathogenic mechanisms [28], these data imply that SLIT might also be a promising treatment option for allergic endotypes with a component of increased neutrophil numbers. Finally, we also evaluated HDM SLIT in a therapeutic setting and found that it led to reduced peribronchial and perivascular inflammation in the lung tissue. In addition, SLIT treatment was accompanied by a tendency towards increased allergen-specific IgA levels. These data confirm the observations of Tourdot et al. [29] who described therapeutic SLIT effects in a systemic sensitization model with alum as the adjuvant.

Several human studies have described changes in antibody responses following SLIT, involving decreased allergen-specific serum IgE, and increased IgG1 and IgG4 levels [30]. Multiple human studies of SLIT for aero- and food allergens have shown that an increase in serum and salivary IgA is associated with clinical efficacy, generally after a year or more of treatment. We also observed a trend towards increased allergen-specific IgA levels in the lavage of SLIT-treated animals even in rather short time protocols which, if further validated, may support the notion that the enhancement of local IgA production may contribute to SLIT efficacy.

With the availability of efficient HDM SLIT models, we also aimed to obtain additional insights into the possible underlying local cellular effects of the treatment. Interestingly, we observed a significantly diminished proportion of $\gamma \delta$ T cells in lung tissue after SLIT treatment while the ratio of $\mathrm{CD} 4+$ versus $\mathrm{CD} 8+$ cells and the number of regulatory $\mathrm{T}$ cells $(\mathrm{CD} 4+\mathrm{CD} 25+\mathrm{Foxp} 3+)$ remained unchanged or only slightly altered compared to shamtreated animals. An evident tissue accumulation of $\gamma \delta \mathrm{T}$ cells was observed in different experimental models of eosinophilic airway inflammation and in the airways of allergic human subjects [31]. Experimental depletion of $\gamma \delta$ $\mathrm{T}$ cells has been associated with an impairment of eosinophil accumulation in inflamed tissue [31]. Some data also imply a role of $\gamma \delta$ T cells in neutrophil influx during airway inflammation. In nonallergic in vivo experimental models it has been shown that $\gamma \delta$-T cell receptor-deficient mice show decreased neutrophil accumulation due to the impairment of chemokines like CXCL1 and CXCL2 [31]. Thus, a reduction in the frequency of $\gamma \delta \mathrm{T}$ cells at the site of inflammation may represent part of the mechanisms by which SLIT reduces features of allergic airway inflammation. Furthermore, we observed significantly increased numbers of $\mathrm{CD} 8+\mathrm{CD} 25+\mathrm{IFN} \gamma+$ cells in the lungs of SLIT-treated animals. Numerous studies provide evidence for a potential role for CD8+ T cells in the pathogenesis of allergic disease, both in animal models and hu-
Hagner/Rask/Brimnes/Andersen/Raifer/ Renz/Garn 
man systems [32]. Tc1 cells can superimpose a Th1-biased inflammation over Th2 response and are capable of actively suppressing Th2 inflammation, especially if present prior to sensitization [33]. Although the underlying mechanism remains unclear, CD8 T cell-derived IFN $\gamma$ was shown to play an important role in the attenuation of allergic lung inflammation [34]. A recently published paper by Tang et al. [35] showed that the inhibition of eosinophilia by CD8 T cells was highly dependent on IFN $\gamma$ production and their Tc phenotype.

Induction of peripheral tolerance mainly characterized by the generation of allergen-specific Treg cells is a central mechanism of allergen AIT $[1,36]$. Actually, elevated numbers of Foxp3+ Tregs were detected in the oral mucosa and increased frequencies of IFN $\gamma / \mathrm{IL}-10$-secreting allergen-specific CD4+ T cells in peripheral blood of humans [37-41]. In contrast, we did not observe a significant difference in the proportion of CD4+CD25+ Foxp3+ Treg cells and only a slightly higher frequency of CD4+CD25+IL-10+ T cells. However, in the supernatants of Der f restimulated lymph node cells, we found a suppression of cytokines from all major $\mathrm{T}$ cell subclasses (IL-5, IL-13, IL-17, IL-10), suggesting a generalized, subclass-independent downregulation of $\mathrm{T}$ cell activities.
This included IL-10, which is not selectively produced by Tregs, but in significant amounts by Th2 cells [42].

Altogether, our results document the prophylactic and therapeutic efficacy of HDM SLIT in a clinically relevant mouse model of allergic airway inflammation and reveal new insights into the underlying immune mechanisms in the lung. This might be a promising approach for the treatment of allergic asthma and is further substantiated by recently published publications of clinical trials with SQ HDM SLIT tablet treatment $[2-6,17]$.

\section{Acknowledgements}

The authors would like to thank Sandra Urioste, Thomas Ruppersberg, Sophia Bernhardt and Wilma Hastedt for technical assistance. This study was supported by ALK-Abelló.

\section{Disclosure Statement}

C.R., J.B. and P.S.A. are employees at ALK-Abelló. The authors declare no financial or commercial conflicts of interest. Prof. Harald Renz has received research funding without restraint from ALK-Abelló A/S.

\section{References}

1 Jutel M, Akdis CA: Novel immunotherapy vaccine development. Curr Opin Allergy Clin Immunol 2014;14:557-563.

2 Mosbech H, Canonica GW, Backer V, Blay F de, Klimek L, Broge L, et al: SQ house dust mite sublingually administered immunotherapy tablet (ALK) improves allergic rhinitis in patients with house dust mite allergic asthma and rhinitis symptoms. Ann Allergy Asthma Immunol 2015;114:134-140.e1.

3 Nolte H, Maloney J, Nelson HS, Bernstein DI, $\mathrm{Lu} \mathrm{S,} \mathrm{Li} \mathrm{Z,} \mathrm{et} \mathrm{al:} \mathrm{Onset} \mathrm{and} \mathrm{dose-related} \mathrm{effi-}$ cacy of house dust mite sublingual immunotherapy tablets in an environmental exposure chamber. J Allergy Clin Immunol 2015;135: 1494-1501.e6.

4 Blay F de, Kuna P, Prieto L, Ginko T, Seitzberg D, Riis B, et al: SQ HDM SLIT-tablet (ALK) in treatment of asthma - post hoc results from a randomised trial. Respir Med 2014;108: 1430-1437.

5 Demoly P, Emminger WRD, Backer V, Tommerup L, Klein-Tebbe J: Effective treatment of house dust mite-induced allergic rhinitis with 2 doses of the SQ HDM SLIT-tablet: results from a randomized, double-blind, placebo-controlled phase III trial. J Allergy Clin Immunol 2016;137:444-451.e8.
6 Mosbech H, Deckelmann R, de Blay F, Pastorello EA, Trebas-Pietras E, Andres LP, et al: Standardized quality (SQ) house dust mite sublingual immunotherapy tablet (ALK) reduces inhaled corticosteroid use while maintaining asthma control: a randomized, double-blind, placebo-controlled trial. J Allergy Clin Immunol 2014;134:568-575.e7.

7 Bergmann K, Demoly P, Worm M, Fokkens WJ, Carrillo T, Tabar AI, et al: Efficacy and safety of sublingual tablets of house dust mite allergen extracts in adults with allergic rhinitis. J Allergy Clin Immunol 2014;133:16081614.e6.

8 Creticos PS, Maloney J, Bernstein DI, Casale T, Kaur A, Fisher R, et al: Randomized controlled trial of a ragweed allergy immunotherapy tablet in North American and European adults. J Allergy Clin Immunol 2013;131: 1342-1349.e6.

9 Didier A, Malling H, Worm M, Horak F, Sussman G, Melac M, et al: Post-treatment efficacy of discontinuous treatment with 300IR 5 -grass pollen sublingual tablet in adults with grass pollen-induced allergic rhinoconjunctivitis. Clin Exp Allergy 2013;43:568-577.
10 Nolte H, Hébert J, Berman G, Gawchik S, White M, Kaur A, et al: Randomized controlled trial of ragweed allergy immunotherapy tablet efficacy and safety in North American adults. Ann Allergy Asthma Immunol 2013;110:450-456.e4.

11 Durham SR, Emminger W, Kapp A, de Monchy JG, Rak S, Scadding GK, et al: SQ-standardized sublingual grass immunotherapy: confirmation of disease modification 2 years after 3 years of treatment in a randomized trial. J Allergy Clin Immunol 2012;129:717-725.e5.

12 Moller C, Dreborg S, Ferdousi HA, Halken S, Host A, Jacobsen L, et al: Pollen immunotherapy reduces the development of asthma in children with seasonal rhinoconjunctivitis (the PAT-study). J Allergy Clin Immunol 2002;109:251-256.

13 Niggemann B, Jacobsen L, Dreborg S, Ferdousi HA, Halken S, Host A, et al: Five-year follow-up on the PAT study: specific immunotherapy and long-term prevention of asthma in children. Allergy 2006;61:855-859.

14 Jacobsen L, Niggemann B, Dreborg S, Ferdousi HA, Halken S, Host A, et al: Specific immunotherapy has long-term preventive effect of seasonal and perennial asthma: 10-year follow-up on the PAT study. Allergy 2007;62:943-948. 
15 Valovirta E, Berstad AKH, de Blic J, Bufe A, Eng $P$, Halken S, et al: Design and recruitment for the GAP trial, investigating the preventive effect on asthma development of an SQ-standardized grass allergy immunotherapy tablet in children with grass pollen-induced allergic rhinoconjunctivitis. Clin Ther 2011;33:15371546.

16 Allam J, Novak N: Immunological mechanisms of sublingual immunotherapy. Curr Opin Allergy Clin Immunol 2014;14:564569.

17 Corzo JL, Carrillo T, Pedemonte C, Plaza Martin AM, Martin Hurtado S, Dige E, et al: Tolerability during double-blind randomized phase I trials with the house dust mite allergy immunotherapy tablet in adults and children. J Investig Allergol Clin Immunol 2014;24: 154-161.

18 Woodhead JS, Weeks I: Magic Lite design and development. J Biolumin Chemilumin 1989; 4:611-614.

19 Alrifai M, Marsh LM, Dicke T, Kılıç A, Con$\operatorname{rad}$ ML, Renz H, et al: Compartmental and temporal dynamics of chronic inflammation and airway remodelling in a chronic asthma mouse model. PLoS One 2014;9:e85839.

20 Hamelmann E, Schwarze J, Takeda K, Oshiba A, Larsen GL, Irvin CG, et al: Noninvasive measurement of airway responsiveness in allergic mice using barometric plethysmography. Am J Respir Crit Care Med 1997;156: 766-775.

21 Moingeon P, Batard T, Fadel R, Frati F, Sieber $\mathrm{J}$, van Overtvelt L: Immune mechanisms of allergen-specific sublingual immunotherapy. Allergy 2006;61:151-165.

22 Razafindratsita A, Saint-Lu N, Mascarell L, Berjont N, Bardon T, Betbeder D, et al: Improvement of sublingual immunotherapy efficacy with a mucoadhesive allergen formulation. J Allergy Clin Immunol 2007;120:278285.

23 Rask C, Brimnes J, Lund K: Shorter dosing intervals of sublingual immunotherapy lead to more efficacious treatment in a mouse model of allergic inflammation. Scand J Immunol 2010;71:403-412.

24 Tourdot S, Airouche S, Berjont N, Moussu H, Betbeder D, Nony E, et al: Efficacy of sublingual vectorized recombinant Bet $\mathrm{v}$ la in a mouse model of birch pollen allergic asthma. Vaccine 2013;31:2628-2637.

25 Yu H, Li X, Guo H, Liu Z, Ran P, Ji K, et al: Sublingual immunotherapy efficacy of Dermatophagoides farinae vaccine in a murine asthma model. Int Arch Allergy Immunol 2010;152:41-48.

26 Wakahara K, Tanaka H, Takahashi G, Tamari M, Nasu R, Toyohara T, et al: Repeated instillations of Dermatophagoides farinae into the airways can induce Th2-dependent airway hyperresponsiveness, eosinophilia and remodeling in mice: effect of intratracheal treatment of fluticasone propionate. Eur J Pharmacol 2008;578:87-96.

27 Ulrich K, Hincks JS, Walsh R, Wetterstrand EC, Fidock MD, Sreckovic S, et al: Anti-inflammatory modulation of chronic airway inflammation in the murine house dust mite model. Pulm Pharmacol Ther 2008;21:637-647.

28 Agache I, Akdis C, Jutel M, Virchow JC: Untangling asthma phenotypes and endotypes. Allergy 2012;67:835-846.

29 Tourdot S, Airouche S, Berjont N, Silveira A, Mascarell L, Jacquet A, et al: Evaluation of therapeutic sublingual vaccines in a murine model of chronic house dust mite allergic airway inflammation. Clin Exp Allergy 2011;41: 1784-1792.

30 Fujita $\mathrm{H}$, Meyer $\mathrm{N}$, Akdis $\mathrm{M}$, Akdis CA: Mechanisms of immune tolerance to allergens. Chem Immunol Allergy 2012;96:30-38.

31 De Oliveira Henriques MD, Penido C: $\gamma \delta$ T lymphocytes coordinate eosinophil influx during allergic responses. Front Pharmacol 2012;3:200.

32 Ogg GS: T-cell immunotherapy of allergic disease: the role of CD8+ T cells. Curr Opin Allergy Clin Immunol 2003;3:475-479.

33 Wells JW, Cowled CJ, Giorgini A, Kemeny DM, Noble A: Regulation of allergic airway inflammation by class I-restricted allergen presentation and CD8 T-cell infiltration. J Allergy Clin Immunol 2007;119:226-234.

34 Takeda K, Dow SW, Miyahara N, Kodama T, Koya $\mathrm{T}$, Taube $\mathrm{C}$, et al: Vaccine-induced CD8+ T cell-dependent suppression of airway hyperresponsiveness and inflammation. J Immunol 2009;183:181-190.

35 Tang Y, Guan SP, Chua BY, Zhou Q, Ho AW, Wong $\mathrm{KH}$, et al: Antigen-specific effector CD8 $\mathrm{T}$ cells regulate allergic responses via IFN- $\gamma$ and dendritic cell function. J Allergy Clin Immunol 2012;129:1611-1620.e4.

36 Calderon MA, Casale TB, Nelson HS, Demoly P: An evidence-based analysis of house dust mite allergen immunotherapy: a call for more rigorous clinical studies. J Allergy Clin Immunol 2013;132:1322-1336

37 Akdis CA, Blesken T, Akdis M, Wuthrich B, Blaser K: Role of interleukin 10 in specific immunotherapy. J Clin Invest 1998;102:98-106.

38 van Overtvelt $L$, Lombardi V, Razafindratsita A, Saint-Lu N, Horiot S, Moussu H, et al: IL10 -inducing adjuvants enhance sublingual immunotherapy efficacy in a murine asthma model. Int Arch Allergy Immunol 2008; 145 : 152-162.

39 Mascarell L, Saint-Lu N, Moussu H, Zimmer A, Louise A, Lone Y, et al: Oral macrophagelike cells play a key role in tolerance induction following sublingual immunotherapy of asthmatic mice. Mucosal Immunol 2011;4:638647

40 O'Hehir RE, Gardner LM, de Leon MP, Hales BJ, Biondo M, Douglass JA, et al: House dust mite sublingual immunotherapy. Am J Respir Crit Care Med 2009;180:936-947.

41 Bohle B, Kinaciyan T, Gerstmayr M, Radakovics A, Jahn-Schmid B, Ebner C: Sublingual immunotherapy induces IL-10-producing $\mathrm{T}$ regulatory cells, allergen-specific T-cell tolerance, and immune deviation. J Allergy Clin Immunol 2007;120:707-713.

42 Saraiva M, O'Garra A: The regulation of IL-10 production by immune cells. Nat Rev Immunol 2010;10:170-181. 